\title{
Geología y geotecnia del monumento
}

\section{J. L. Justo}

Catedrático del área de Ingeniería del Terreno E.T.S. Arquitectura Universidad de Sevilla

\section{Geología}

Carmona se encuentra enmarcada en plena depresión del Guadalquivir. Sólo se van a describir los sedimentos autóctonos, que son los que intervienen en el problema de los desprendimientos y deslizamientos de Carmona. Estos sedimentos pertenecen al mioceno superior-plioceno, y se distinguen, de muro a techo, tres formaciones: margas azules $y$ grises, margas azules $y$ grises con calcarenitas, areniscas y limos amarillos.

La potencia de las margas azules y grises es prácticamente imposible de evaluar, pero por datos de sondeos se deduce que debe ser superior a $300 \mathrm{~m}$. La edad de la formación puede expresarse como Tortoniense superior (parte alta) -Messiniensse- iPlioceno basal? En algunos tramos las margas son, en realidad, arcillas margosas. La fracción de arcilla suele oscilar entre el 40 y el $60 \%$, con una media del $44 \%$ de illita, $40 \%$ de esmectitas y el resto caolinita y clorita. Tienen como media un $22 \%$ de carbonatos.

Las margas azules y grises con calcarenitas forman la transición a las areniscas y limos superiores. Su potencia no sobrepasa los 15-20 m. Los abundantes deslizamientos de ladera ocasionados por las calcarenitas sobre las margas azules cuando están húmedas, como consecuencia de la plasticidad de éstas, cubren con frecuencia esta formación.

Las calcarenitas, areniscas y limos amarillos forman la capa superior de los Alcores. La potencia de esta formación es variable, y en las inmediaciones de Carmona debe sobrepasar los $30 \mathrm{~m}$ de espesor. Pertenecen al Messiniense terminal - ¿Plioceno basal? La composición mineralógica es mayoritaria en calcita (30-85\%) y cuarzo (media 20\%). La formación de estos materiales se sitúa en un medio somero, de plataforma marina abierta. Es un sedimento muy grosero (arena gruesa), con más del $80 \%$ de lamelibranquios de concha fina.

\section{Geomorfología y neotecnología}

La posición que ocupan las calcarenitas, encima de margas gris-azuladas, así como la topografía existente, son la causa de la gran canti- dad de deslizamientos de ladera en toda la cornisa de calcarenitas entre Carmona -El Viso del Alcor- Alcalá de Guadaira. Esto conlleva que sea difícil determinar la tectónica de fractura, porque parte de las fracturas-diaclasas corresponden a grietas provocadas por los mismos deslizamientos.

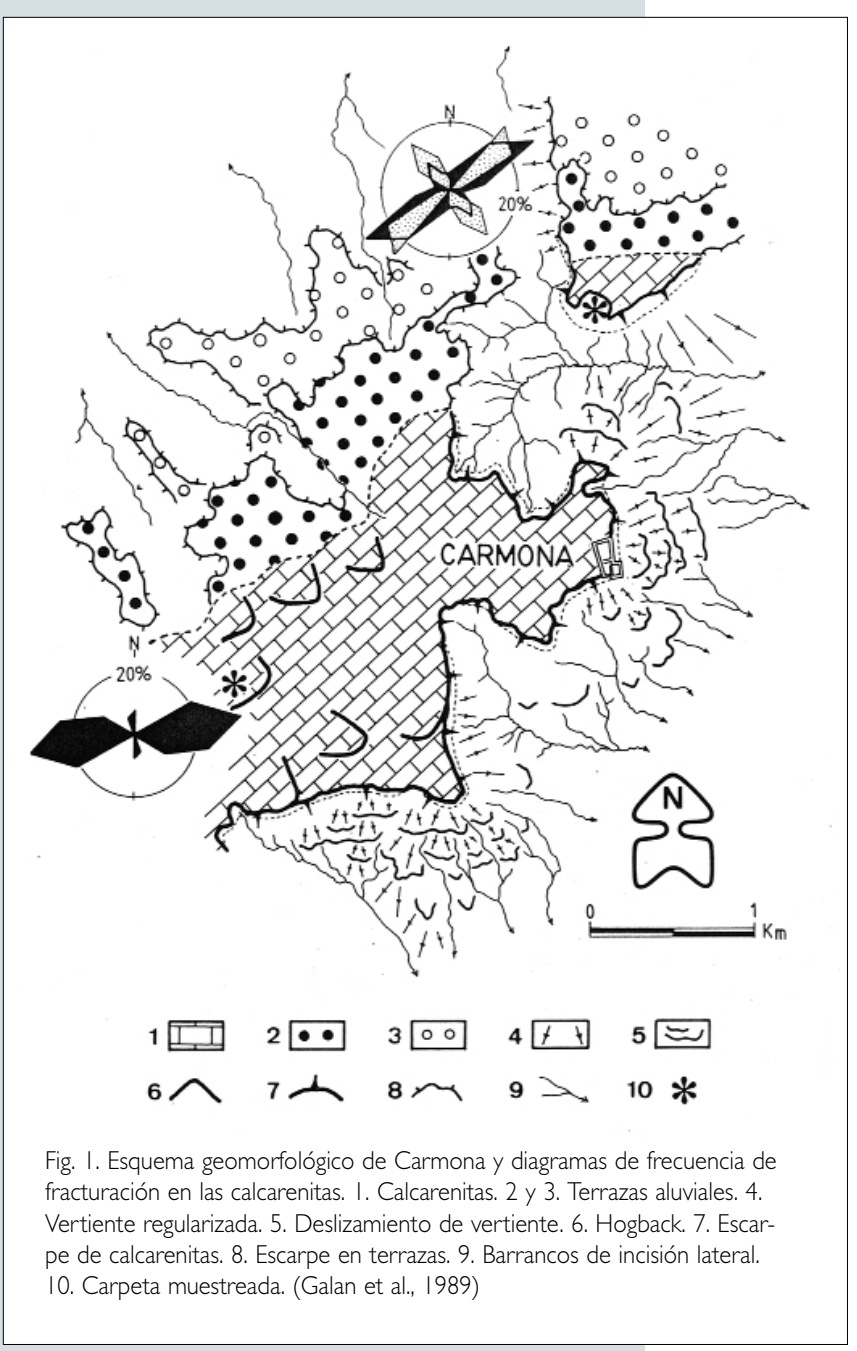

La tectónica post-pliocena ha sido minuciosamente descrita por Viguier (1974), el cual define las principales alineaciones de fallas y la edad de su funcionamiento. Destaca el sistema Alcor, de dirección $\mathrm{N} 60^{\circ} \mathrm{E}$, de edad pliocena superior, que recorre los Alcores por su flanco septentrional y otro conjunto de fallas acompañantes, de dirección aproximada NNO-SSE, que compartimentan este relieve elevado en calcarenitas; sobre todo en las proximidades de Carmona. 
Se observan dos series de diaclasas: una más antigua de dirección NE-SO a E-O, y otra más reciente de dirección NO-SE.

La configuración del relieve, las características litológicas del escarpe de los Alcores y la orientación y densidad del diaclasado originan movimientos de material rocoso a lo largo de las vertientes. La cartografía geomorfológica (Fig. I) confirma un elevado número de deslizamientos de vertiente que, favorecidos por las margas infrayacentes, desplazan importantes volúmenes de roca calcarenita en bloques de los escarpes, cuyas dimen-
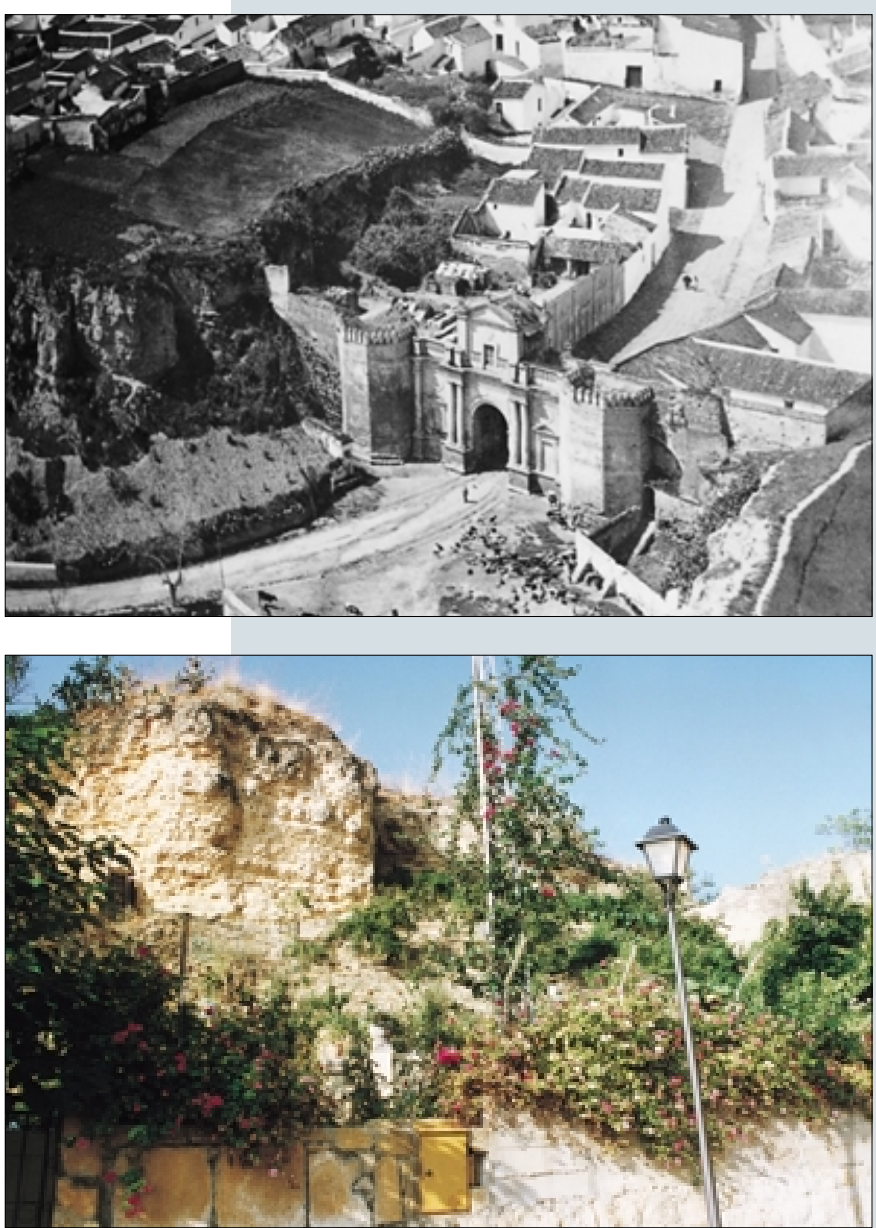

Fig. 2. Fotografía antigua de la Puerta de Córdoba

Fig. 3. Estribo derecho

\section{Referencias}

siones ya habían sido previamente definidas por intersección de diaclasas.

\section{Geotecnia de la Puerta de Córdoba}

La Puerta de Córdoba está encajada entre bloques de calcarenitas (Fig. 2).

En el sondeo SI (v. Justo, 1997), ejecutado en la parte superior del estribo izquierdo, aparece la marga azul a $17 \mathrm{~m}$ de profundidad, y en el sondeo S2, realizado en la base de la Puerta de Córdoba se presenta a sólo 4,50 m. La existencia de un manantial en el bloque de albero, indica la existencia de posibles niveles freáticos colgados.

La figura 3 muestra el estribo derecho tras ser limpiado. En el albero aparecen diaclasas verticales que explican los derrumbes que se producen. En él aparecen cuevas producidas por la actividad humana que colaboran en su deterioro.

\section{Soluciones}

Para paliar el proceso de erosión al que está sometido el albero se podrían utilizar bulones entre 2 y $3 \mathrm{~m}$ de longitud, en dos columnas verticales, la primera de ellas a $2 \mathrm{~m}$ del apoyo de la puerta, y la $2^{\mathrm{a}}$ a $2 \mathrm{~m}$ de la anterior. La distancia vertical podría ser de $3 \mathrm{~m}$, con lo cual el número de bulones de cada fila sería de 4 (en total 8 bulones por estribo). Las perforaciones deben realizarse en seco, debido a la descomposición que presenta el albero.

El albero podría protegerse, donde no hay vegetación, con un gunitado del mismo color que el albero. Los bulones deben quedar no vistos. La principal dificultad está en montar las plataformas para la ejecución de los trabajos.

Otra posible solución es una red anclada. Si la abertura de la malla es suficientemente amplia esta red causa muy escaso impacto visual. La red se podría completar con plantaciones autóctonas que acabarían ocultando dicha red.
Galán, E., Pérez Rodríguez, J.L., Díaz, Mª G., González, Mª., Maqueda, C., Polvorinos, A., Rodríguez, J., y Ruiz Carvajal, J., 1989. Geología de Sevilla y sus alrededores y Características Geotécnicas de los Suelos del Area Urbana. Ayuntamiento de Sevilla.
Justo, J.L., 1997. Informe geotécnico sobre los estrubos de la Puerta de Córdoba (Carmona). Instituto Andaluz del Patrimonio Histórico. Informe no publicado.

Viguier, C., 1974. Le Néogène de l'Andalusie Nord Occidentale. Thèse d'Etat, Univertisé de Bordeaux. 